\title{
Mini-Review
}

\section{Control of Th2-Mediated Inflammation by Regulatory T Cells}

\author{
K. Venuprasad Poojary, ${ }^{*}$ Yi-chi M. Kong, ${ }^{*}$ \\ and Michael A. Farrar ${ }^{\dagger}$ \\ From the Karmanos Cancer Institute and the Department of \\ Immunology and Microbiology," Wayne State University, Detroit, \\ Michigan; and the Department of Laboratory Medicine and \\ Pathology, ${ }^{\dagger}$ Center for Immunology, The Cancer Center, \\ University of Minnesota, Minneapolis, Minnesota
}

\begin{abstract}
Allergic diseases and asthma are caused by dysregulated Th2-type immune responses, which drive disease development in susceptible individuals. Immune tolerance to allergens prevents inflammatory symptoms in the respiratory mucosa and provides protection against inflammation in the airways. Increasing evidence indicates that Foxp3 + regulatory $T$ cells (Tregs) play a critical role in immune tolerance and control Th2-biased responses. Tregs develop in the thymus from $\mathrm{CD}^{+} \mathrm{T}$ cells (natural Tregs) and also in the periphery by the conversion of naive $C D 4^{+} \mathrm{T}$ cells (induced Tregs). Increased susceptibility to allergy and airway inflammation is hypothesized to result from impaired development and function of Tregs. Thus, strategies to induce allergen-specific Tregs hold great promise for treatment and prevention of asthma. (Am J Pathol 2010, 177:525-531; DOI: 10.2353/ajpath.2010.090936)
\end{abstract}

The incidence of chronic inflammatory lung diseases, such as asthma, has increased dramatically in recent years in industrialized countries. Asthma is characterized by airway hyperresponsiveness, chronic pulmonary eosinophilia, elevated serum IgE, excessive mucus production, and airway remodeling. ${ }^{1}$ These symptoms are believed to result from interactions between environmental stimuli and a variety of genes influencing immune and respiratory function. In susceptible individuals, environmental stimuli induce immune dysfunction, which drives Th2 responses to otherwise harmless antigens. Although it is clear that Th2 responses drive pathological changes in asthma, the mechanisms that develop in vivo to prevent Th2-driven inflammation in nonallergic individuals are not clear.
The identification of reciprocally inhibitory functions of Th1 and Th2 cells led to the concept that a defect in Th1type immune responses resulted in deregulated Th2 responses and increased incidence of allergic diseases. Based on this concept, the hygiene hypothesis was proposed, which posits that decreased exposure to Th1-inducing infections, such as mycobacteria and viruses, leads to unconstrained development of Th2 responses and increased incidence of allergic diseases., ${ }^{1,2}$ However, this simple explanation is insufficient to explain many experimental findings. First, Th1-responding cells are not always beneficial in allergic asthma and have been reported to contribute to and exacerbate this disease. ${ }^{3,4}$ For example, adoptive transfer of Th1 cells resulted in enhanced airway eosinophilia and Th2 responses. ${ }^{5}$ Similarly, inhaled recombinant interferon- $\gamma$ did not significantly alter clinical symptoms in humans. ${ }^{6}$ Second, epidemiological data suggest a parallel increase in Th2-mediated allergic diseases and Th1-mediated autoimmune diseases, such as Type 1 diabetes, multiple sclerosis, and rheumatoid arthritis. ${ }^{7}$ These findings suggest that other regulatory mechanisms play a critical role in inhibiting the development of inappropriate Th2 (and Th1) responses.

The respiratory mucosal surface is exposed to a vast quantity of environmental antigens, which challenge the immune system. Thus, the immune system must discriminate between, and appropriately respond to, both pathogenic and innocuous antigens. Under nonallergic circumstances, soluble proteins do not provoke a strong immune response, but instead induce a state of antigenspecific tolerance or hyporesponsiveness. T cell tolerance is achieved through central and peripheral mechanisms. Central tolerance encompasses deletion of T cells during negative selection, as well as selection of Tregs in the thymus. On the other hand, peripheral tolerance encompasses the mechanisms that lead to $T$ cell tolerance

\footnotetext{
Supported by National Institutes of Health grant RC146576A

Accepted for publication March 22, 2010.

Address reprint requests to K. Venuprasad Poojary, Ph.D., 110 E. Warren Ave Mail code-PRO4IM, Detroit, Ml 48201; or Michael A. Farrar, Ph.D., Center for Immunology, University of Minnesota, 2101 6th Street Southeast 2-116 Medical Biosciences Building, Minneapolis, MN 55455. E-mail: poojaryv@karmanos.org or farra005@umn.edu.
} 
to antigens; these include ignorance, deletion, anergy induction, and active suppression by CD4+Foxp3+ regulatory $\mathrm{T}$ cells (Tregs).

There is growing evidence that Tregs play an important role in inhibiting Th2-mediated responses to allergens and maintaining immune tolerance. Studies in mouse models have shown that peripheral $\mathrm{CD}^{+}{ }^{+} \mathrm{T}$ cell tolerance, induced by respiratory exposure to allergens, prevents the development of allergen-induced airway hyperresponsiveness. $^{8}$ Likewise, we have reported that intravenous administration of soluble antigens results in antigen-specific anergy in Th2 cells and reduces airway inflammation. $^{9}$ In this review we summarize current knowledge of Treg development and their role in the regulation of Th2-mediated allergic responses.

\section{Treg Repertoire Development}

Tregs develop in the thymus from CD4 single positive thymocytes (called natural Tregs or nTregs), and also in the periphery by the conversion of naïve CD4 T cells in response to specific tolerogenic stimuli (called induced Tregs or iTregs). Although there is consensus that nTregs develop early to suppress autoimmune responses, as recently reviewed by Kong et $a{ }^{10}{ }^{10}$ it is presently unclear whether nTregs and iTregs serve different physiological needs or have some redundant functions. Moreover, their relative contribution to the total pool of Tregs in secondary lymphoid organs or nonlymphoid tissues during the course of immune challenge remains to be determined.

\section{Thymus-Derived nTregs}

The notion that Tregs develop in the thymus came from neonatal thymectomy experiments. Thymectomy at day 3 after birth in normal mice resulted in autoimmune damage of various organs, such as the thyroid, stomach, and ovaries. Inoculation of normal CD4 ${ }^{+} \mathrm{T}$ cells and CD4+CD8thymocytes inhibited the development of autoimmunity. ${ }^{11}$ These studies suggested that normal animals harbor not only pathogenic, self-reactive $T$ cells but also inhibitory $T$ cells that suppress immune responses detrimental to self. Subsequent efforts to identify Tregs resulted in the elucidation of first CD4 ${ }^{12,13}$ and then CD25, as the specific Treg markers. These CD4+CD25+Tregs constitute approximately 5 to $15 \%$ of peripheral $\mathrm{CD}^{+} \mathrm{T}$ cells and play a nonredundant role in maintaining immunological self-tolerance and homeostasis of the immune network. ${ }^{11}$

Tregs express the Fork-head transcription factor Foxp3, which was first identified as the defective gene responsible for wide spread autoimmune disease in scurfy mice and in humans with IPEX, the immune dysregulation, polyendocrinopathy, enteropathy, and $x$-linked syndrome. ${ }^{11}$ Foxp3 is specifically expressed in CD4+CD25+ Tregs and ectopic expression of Foxp3 in CD4+CD25- cells converts them into Tregs, capable of suppressing proliferation of other $\mathrm{T}$ cells in vitro and inhibiting autoimmunity in vivo. ${ }^{14}$ Despite our growing knowledge of Treg biology, the molecular mechanism that regulates expression of Foxp3 in Tregs during their development is not fully understood. Studies have suggested that nTregs develop from CD4 single positive thymocytes, which acquire Foxp3 expression during ontogeny. More recent work from our lab and that of Chyi Hsieh's has demonstrated that Tregs undergo development via a two-step process. ${ }^{15,16}$ The first step requires TCR/ $\mathrm{MHC} \|^{16}$ and CD28-dependent signals, ${ }^{17}$ which results in the generation of a CD4+CD25+CD122+ GITR ${ }^{\text {hiFoxp3 }}{ }^{-}$ Treg progenitor. The effect of CD28 appears to involve the nuclear factor (NF) $\mathrm{B}$ pathway, as CD28 knock-in mice defective in $\mathrm{NF} \kappa \mathrm{B}$ activation exhibit a clear reduction in Tregs. Consistent with this notion, carma ${ }^{-/-}$mice also lack Treg progenitors ${ }^{18}$; this appears to reflect a specific role for c-Rel, as $\mathrm{c}-\mathrm{rel}^{-1-}$ but not NF $\kappa_{\mathrm{B}} 1^{-1-}$ mice lack Tregs ${ }^{19,20}$ and Treg progenitors. ${ }^{17}$ Thus, the molecular mechanisms underlying the development of Treg progenitors are just beginning to be characterized.

The second step of Treg development involves cytokine-dependent conversion of Treg progenitors into mature Foxp3+ Tregs. This is consistent with the observation that interleukin (IL)-2R $\gamma \mathrm{c}^{-/-}$mice are devoid of Tregs. ${ }^{14} \mathrm{IL}-2$ is likely the only physiologically relevant cytokine involved in this process. Several pieces of evidence support this statement. First, IL-2 is by far the most effective cytokine at driving the conversion of sorted Treg progenitors into mature Tregs in vitro; IL-7 and IL-15 also can do this, but quite poorly. ${ }^{16,21}$ Second, although Tregs can be observed in il $2^{-/-}$and $i l 2 r \alpha^{-/-}$mice, these Tregs show aberrantly high expression of IL-7R $\alpha$ and IL-15R $\alpha$ chains; short-term exposure of Tregs obtained from il2 ${ }^{-/-}$ mice to IL-2 rapidly reduces expression of both cytokine receptors. ${ }^{21}$ Finally, in mixed bone marrow chimeras using wild-type and $i / 2 \mathrm{r}^{-1-}$ bone marrow, only the wildtype bone marrow-derived cells effectively generated Tregs. ${ }^{22}$ Thus, under physiological conditions, IL-2 appears to be the only cytokine that effectively drives Treg development.

The process by which IL-2 drives Treg development appears to uniquely require IL-2-dependent activation of the downstream transcription factor, signal transducer and activator of transcription (STAT)5. Mice that lack STAT5 are devoid of Tregs, while transgenic mice expressing a constitutively active form of STAT5 (called STAT5 b-CA) have a greatly expanded population of Tregs. ${ }^{23}$ Moreover, mice expressing IL-2R $\beta$ mutants that can only activate the STAT5 pathway still have Tregs, and crossing the STAT5b-CA transgenic mice to il $2 r \beta^{-1-}$ mice rescues the defect in Treg development normally seen in il $2 r \beta^{-1-}$ mice. ${ }^{23}$ Intriguingly, the STAT5-dependent conversion of Treg progenitors into mature Tregs is blocked by histone deacetylase inhibitors. ${ }^{15}$ The reason for this remains unknown. However, the most likely explanation is that STAT5/histone deacetylase interactions are required for foxp3 transcription; this could involve removal of inhibitory acetyl groups on other transcription factors required for foxp3 transcription or may involve a completely novel mechanism.

A more controversial question involves the role of transforming growth factor (TGF)- $\beta$ in Treg development. nTreg development was shown to be normal in both $\operatorname{tgf-} \beta^{-1-}$ mice and tgf- $\beta$ receptor knock-out mice. ${ }^{24}$ Likewise, we and Chyi Hsieh and colleagues ${ }^{15,16}$ found that in 
vitro conversion of thymic Treg progenitors into mature Tregs did not require TGF- $\beta$. However a separate study found that mice doubly deficient for TGF- $\beta$ and IL-2 exhibit a severe defect in Treg development in the thymus, ${ }^{25}$ suggesting that IL-2 masks the effect of Treg deficiency by expanding the few Tregs that develop in $\operatorname{tgf} \beta^{-1-}$ mice. This finding appears to contradict the observation that conversion of thymic Treg progenitors into mature Tregs does not require TGF- $\beta$. However, these data would be reconciled if TGF- $\beta$ influenced the development of Treg progenitors (step I of the Treg developmental process) but not the IL-2-driven conversion of those cells into mature Tregs (step II of the process).

A final question involves the thymic niche where Treg development occurs. Recent work by Hsieh and colleagues ${ }^{26}$ has demonstrated that the thymic niche for Treg development is likely to be $\sim 100$-fold smaller than that observed for positive selection. Specifically, mice expressing a TCR-transgene derived from nTreg can give rise to Tregs but only do so efficiently if present at very low clonal frequencies. In contrast, the OT-II TCR (specific for an MHC class II/ovalbumin peptide) transgene is incapable of giving rise to Tregs at any clonal frequency. This result suggests that Treg development requires both the appropriate TCR and also interaction with an easily saturable thymic niche. Whether the small size of this thymic Treg niche reflects limiting high affinity antigens, and/or limiting levels of IL-2 remains to be addressed.

\section{Peripheral Generation of iTregs}

In addition to the thymic production of nTregs, naive $\mathrm{CD} 4^{+} \mathrm{T}$ cells in the periphery acquire Foxp3 expression and Treg function in several experimental settings, namely in vitro antigen stimulation in the presence of TGF- $\beta$ or chronic antigen stimulation in vivo. ${ }^{27,28}$ Such iTregs inhibit the development of autoimmunity and inflammation in allergic inflammation models. ${ }^{27}$ For example, using a mouse model of hyper-lgE and asthma, Mucida et $\mathrm{al}^{29}$ demonstrated that iTregs induced in the absence of $n$ Tregs effectively inhibit Th2 responses. To generate this model they crossed influenza Hemagglutininspecific immunoglobulin heavy and light chain knock-in mice with DO11.10 OVA-specific TCR-transgenic mice on a rag-1 knock-out background. These mice develop an exacerbated Th2 response after immunization and respiratory challenge with cognate antigen complex OVA-Hemagglutinin. ${ }^{29}$ However, oral antigen administration before immunization inhibited effector/memory Th2 cell development, class switching to IgE, and airway inflammation. This effect of oral antigen administration was due to the development of antigen-specific CD4+CD25+Foxp3+ Tregs independent of thymic Treg development.

Similarly, it has been demonstrated that nTregs and de novo generated iTregs contribute independently to tumor-specific tolerance. ${ }^{30}$ However, the extent to which such iTregs contribute to the peripheral pool of Tregs, and whether they have a stable phenotype comparable with that of nTregs, is not clear. This is partly due to a lack of reliable markers to distinguish nTregs and iTregs.
Recent studies suggest that there are significant differences in the development, antigen specificity, and stability of suppressor function between nTregs and iTregs. ${ }^{31}$ The development of $n$ Tregs requires high affinity interactions with cognate self peptide-MHC complexes and CD28 costimulation, whereas iTreg development requires weaker suboptimal TCR stimulation and costimulation through CTLA-4. ${ }^{32}$ In vitro studies further show that Foxp3 expression is relatively unstable in iTregs compared with nTregs; when iTregs are restimulated in the absence of TGF- $\beta$, they lose Foxp3 expression and inhibitory function. ${ }^{33}$ This difference in the stability of Foxp3 expression is attributed to the methylation status of $\mathrm{CpG}$ motifs in the Foxp3 locus. ${ }^{33}$ However, the full extent of differences and similarities between iTregs and $\mathrm{nTregs}$ is yet to be defined.

Several studies have suggested that mucosal tissues are a major site of Foxp3+ iTreg development, and several micro-environmental factors may promote or inhibit iTreg development. The presence of IL-6 inhibits Foxp3 expression and promotes $\mathrm{CD}^{+}{ }^{+} \mathrm{T}$ cell differentiation into Th17 effector cells. ${ }^{34}$ Blockade of the IL-6 receptor led to expansion of CD4+CD25+ Tregs in the airway and suppressed airway inflammation. ${ }^{35}$ In addition to IL-6, it has been found that pro-inflammatory cytokines that drive Th1 and Th2 differentiation also inhibit iTreg development. ${ }^{36}$

The vitamin A metabolite retinoic acid (RA) inhibits the IL-6-driven induction of $\mathrm{TH} 17$ cells and promotes antiinflammatory Treg cell differentiation. ${ }^{37}$ CD103+ DCs isolated from the small intestine produce both TGF- $\beta$ and RA, and these DCs efficiently promote Foxp3 expression and iTreg development. ${ }^{38,39}$ RA was shown to enhance TGF- $\beta$ driven Smad3 signaling and inhibit IL-6 and IL-23 receptor expression. ${ }^{40}$ On the other hand, Hill et al ${ }^{41}$ showed that, rather than enhancing TGF- $\beta$ signaling directly in naïve CD4 $T$ cells, RA negatively regulates accompanying CD4+CD44hi effector memory cells. These memory cells actively inhibited TGF- $\beta$ effects through the secretion of a set of cytokines (IL-4, IL-21, and interferon- $\gamma$ ) whose expression was curtailed by RA. Further, using highly purified naive (CD4+CD25-CD44loCD62L+) CD4+T cells, Mucida et al ${ }^{42}$ reported that RA enhanced Foxp3 expression by acting both directly on naïve CD4 T cells and indirectly via inhibitory effects on CD4+CD44hi T cells. Taken together, the net outcome is likely determined by relative levels of various factors present in the tissue microenvironment during $T$ cell activation.

\section{Transcriptional Regulation of Foxp3}

Despite the growing body of data regarding the role of Foxp3 in Treg development and function, relatively little is known about the transcriptional regulation of Foxp3. Specifically, what are the signals that regulate transcription of foxp3 in Tregs? The foxp3 promoter contains NFAT, AP-1, and SP1 binding sites and a TATA and CAAT box ${ }^{43}$ (Figure 1). The core promoter is located $6.5 \mathrm{~kb}$ upstream of the foxp 3 translation start site and the $5^{\prime}$ untranslated region is interrupted by a 6000 bp intron. ${ }^{43}$ The promoter is highly conserved among mice, humans, and rats. 


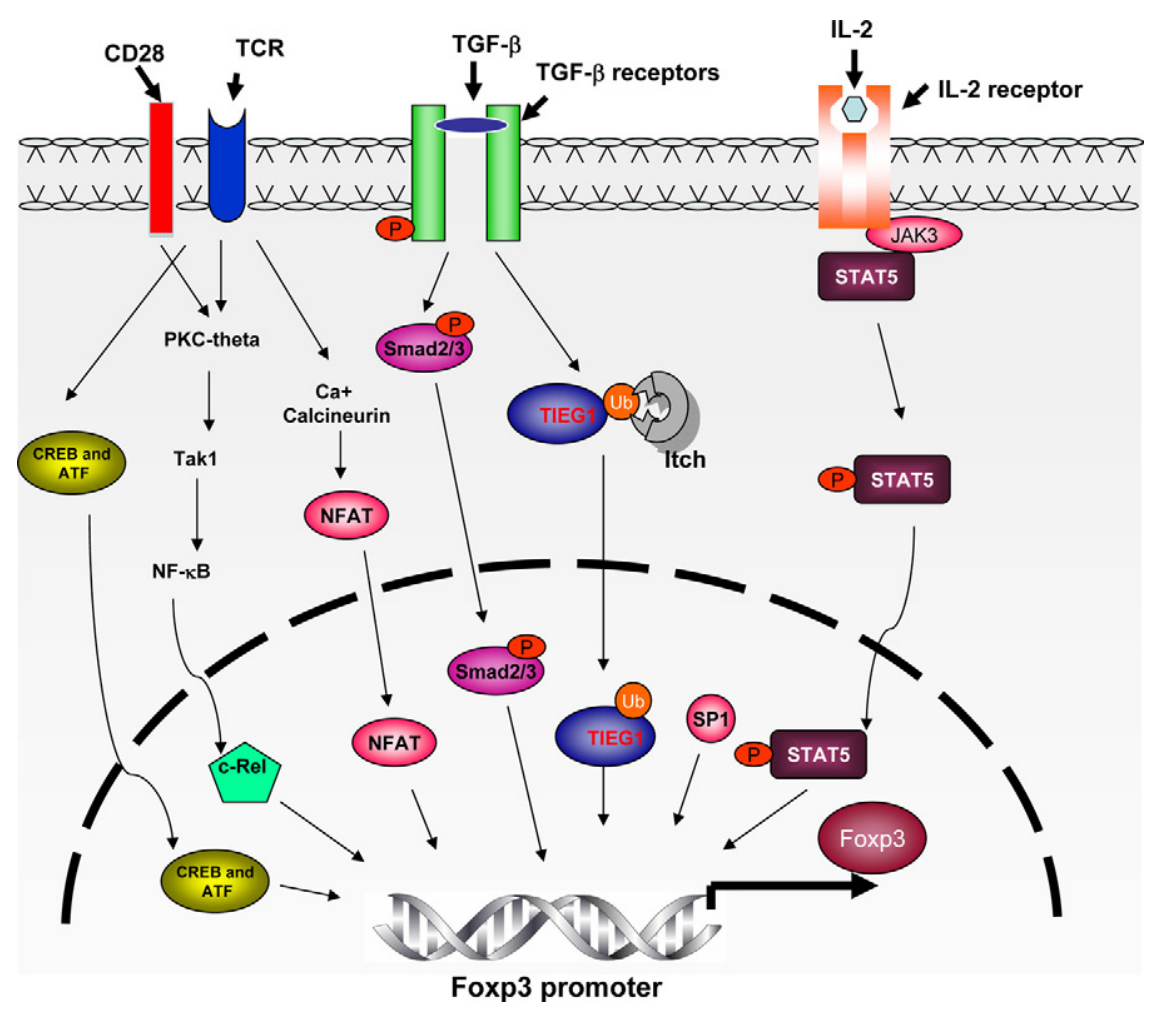

Figure 1. Foxp3 transcription is regulated by multiple transcription factors. Signals triggered by the ligation of TCR, CD28, TGF- $\beta$, and IL- 2 result in the activation of the transcription factors cAMP responsive element binding protein (CREB), activating transcription factor (ATF) $\mathrm{SP} 1, \mathrm{Ca}+$ calcineurin-dependent nuclear factor of activated T cells (NFAT), activator protein 1 (AP1), c-Rel, TGF- $\beta$-inducible early gene 1 (TIEG1), mothers against decapentaplegic homologue 3 (SMAD3), and signal transducer and activator of transcription 5 (STAT5). These transcription factors converge on the Foxp3 promoter to induce Foxp3 expression.

Tregs and effector T cells exhibit differences in the epigenetic modification of the foxp3 promoter and first intron in both mice and humans. Although several signals that induce the expression of Foxp3 have been identified, the precise molecular mechanisms that imprint Foxp3 expression in Tregs is not clear.

Three highly conserved noncoding sequences (CNS 1-3) in the foxp3 locus have been identified. ${ }^{44,45}$ CNS1 is in the promoter region and shows extensive chromatin remodeling in Tregs. CNS2 and CN3 are located in the intronic region of Foxp3. Tone et $\mathrm{al}^{45}$ demonstrated that Smad3 and NFAT cooperatively bind to CNS2, which suggests a model in which TCR and TGF- $\beta$-induced signals converge to regulate the foxp3 promoter. CNS3 contains highly conserved CpG-rich island to which the transcription factors CREB and ATF bind. ${ }^{44}$ Recently, it has been demonstrated that the $\mathrm{c}$-Rel transcription factor controls Treg development by the formation of foxp3specific enhanceosomes and binds to CNS3 as well. ${ }^{19,20}$

Signaling downstream of IL-2R through the JAK-STAT pathway is also critical for foxp3 promoter activity. STAT5a/b is required for optimal induction of foxp3 and binds directly to the foxp3 promoter as well as sites in the first intron. ${ }^{23,46}$ We have demonstrated that TGF- $\beta$ inducible early gene-1(tieg1) binds to the foxp3 promoter and regulates foxp3 promoter activity. E3 ligase Itch-mediated mono-ubiquitination of TIEG1 is essential for its nuclear translocation and binding to the foxp3 promoter (Figure 1). ${ }^{47}$ Another study suggests that TIEG1 binds an upstream enhancer region in the foxp3 promoter in nTregs but not in iTregs. ${ }^{48}$ Several factors also inhibit TGF- $\beta$-induced Foxp3 expression. For example, IL-4-induced STAT6 and GATA3 are reported to bind to the foxp3 promoter and negatively regulate Foxp3 expression. ${ }^{34}$ This suggests a delicate balance of TCR and cytokine receptor signaling regulates Foxp3 expression in Tregs.

\section{Tregs in Allergic Inflammation}

A number of studies have suggested a potential role of Tregs in prevention and regulation of Th2-mediated allergic responses. In animal studies, CD4+CD25+ Tregs inhibited the differentiation of naïve CD4 T cells into Th2 cells and adoptive transfer of CD4+CD25+ Tregs before allergen challenge of sensitized mice resulted in reduced airway hyperresponsiveness and inflammation. ${ }^{49}$ Similarly, depletion of CD25+ cells before delivery of house dust mite allergen led to significantly elevated IgE levels and eosinophilia. ${ }^{50}$ Likewise, the percentages of CD4+CD25+ Tregs and Foxp3 mRNA levels were lower in the bronchoalveolar lavage fluid from children with asthma compared with healthy individuals. ${ }^{51}$

However, the most convincing evidence for a role of Tregs in preventing atopic disease comes from an experiment-of-nature in patients with IPEX syndrome. These $X$-linked multisystem disorders are caused by genetic mutations in the gene encoding Foxp3. The clinical manifestations in these patients not only include autoimmune diseases but also allergic pathologies including eczema, increased serum IgE levels, and eosinophila. ${ }^{11}$ A study by Wan and Flavell ${ }^{52}$ suggests that attenuation of Foxp3 expression promotes Th2-mediated inflammation. The authors inserted a gene cassette co-expressing luciferase and enhanced green fluorescent protein into the 


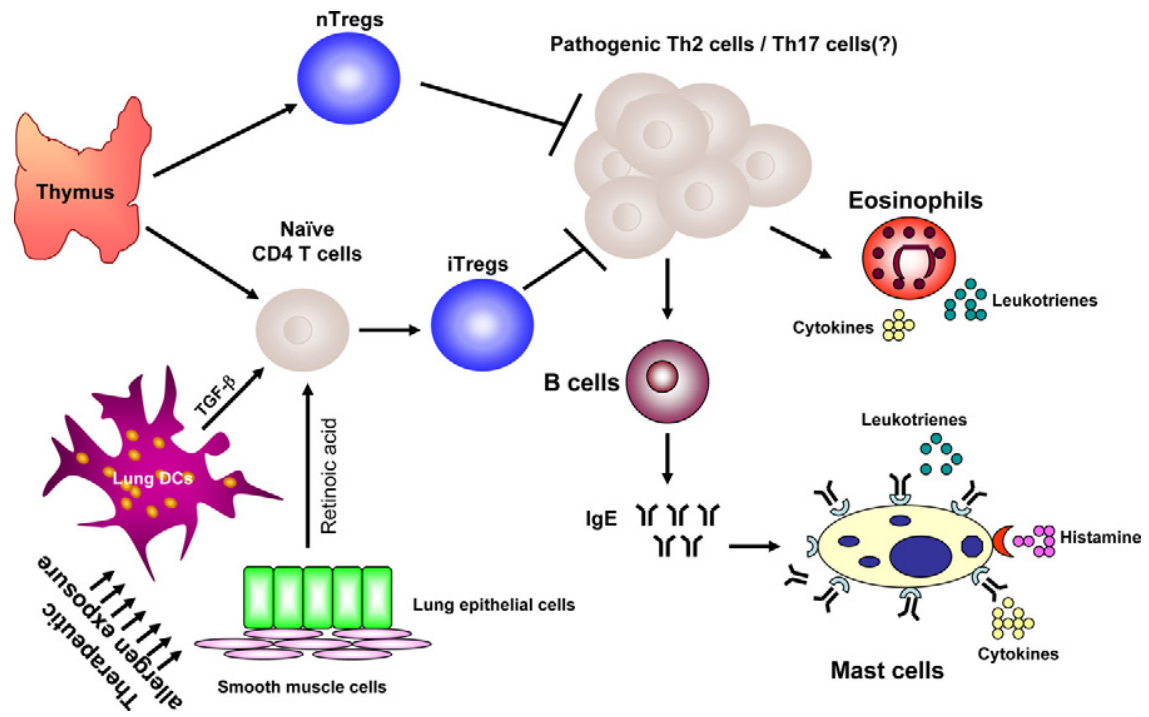

Figure 2. Foxp3+ Tregs regulate Th2-mediated inflammation and allergy. Natural Tregs (nTregs) inhibit priming and effector function of allergenspecific Th2 cells and prevent inflammation and allergy in non-atopic individuals. Induced Tregs (iTregs), which develop via conversion of naïve CD4 T cells into Foxp3 + Tregs during therapeutic exposure to allergens, can also function in this manner. TGF- $\beta$ and retinoic acid (RA) may facilitate such conversion and provide protection against asthma and allergy. $3^{\prime}$-untranslated region of the foxp3 locus of mice to generate a Foxp3-IRES-luciferase-IRES-enhanced green fluorescent protein (FIL/G) allele. This resulted in reduced foxp3 gene expression. Notably, CD4 T cells expressing decreased Foxp3 preferentially became Th2 type effectors even in Th1-polarizing conditions. ${ }^{52}$ These results were further supported by Bluestone and colleagues ${ }^{53}$ who demonstrated that instability of Foxp3 led to generation of pathogenic CD4 memory T cells. All these findings suggest a critical role for Foxp3+Tregs in the pathogenesis of asthma and allergy.

Recently, Th17 cells have been shown to mediate pathogenic inflammatory responses. The presence of TGF- $\beta$ and pro-inflammatory cytokines, such as IL-6, IL23, and IL-21, promotes Th17 differentiation via coordinated upregulation of the orphan nuclear receptor ROR $y$ t. $^{34}$ Considering that Treg and $T_{H} 17$ cell differentiation are cross-regulated, one can speculate that in allergic individuals the balance is skewed toward inflammatory $T_{H} 17$ cells. In fact, increased IL-17 levels are reported in the lungs, sputum, bronchoalveolar lavage fluids, or sera from asthmatics, and the level of IL-17 correlated with the severity of asthma, suggesting a contribution of IL-17 to the pathogenesis of asthma. ${ }^{54}$ Studies using murine asthma models have shown that IL-17 receptor-deficient $\left(i / 17 r^{-1-}\right.$ ) mice exhibit reduced recruitment of neutrophils and eosinophils into the airways, ${ }^{55}$ resulting in impaired priming of Th2 responses. IL-17 has also been shown to induce the release of the eosinophilrecruiting chemokine eotaxin from airway smooth muscle cells, and both IL-17 and IL-17F were able to induce the release of inflammatory mediators from human eosinophils in vitro ${ }^{56,57}$. On the other hand, it has been demonstrated that neutralization of IL-17 at the effector phase of airway inflammation enhances eosinophilic inflammation. ${ }^{55}$ Similarly, IL-4 receptor-deficient mice, which are protected from allergic inflammation, increased IL-17 levels in the lungs that were partially responsible for suppression of lung eosinophilia. ${ }^{55}$ Taken together, these results clearly implicate $\mathrm{IL}-17$ in allergic asthma but a more detailed study on the balance of Treg/Th2/Th17 in allergy and asthma is required.

There is considerable interest in the therapeutic use of Tregs for allergic and asthmatic patients with the aim of providing more effective, specific, and long-lasting treatment. Approaches to shift the balance to Treg-mediated tolerance to allergens have been investigated in mouse models. A study using lower doses of intranasal OVA administration resulted in surface TGF- $\beta+$ Tregs, which inhibited Th2 response via a cell-to-cell contact-dependent mechanism ${ }^{58}$ (Figure 2). Higher doses of antigen exposure through the intranasal route resulted in IL-10 secretion by DCs, which induced allergen-specific Tregs and inhibited lung inflammation in an IL-10-dependent manner. ${ }^{59}$ Similarly, oral administration of OVA resulted in TGF- $\beta$-dependent OVA-specific Tregs, which inhibited lung inflammation. ${ }^{29}$

Recently it has been shown that RALDH-1, the ratelimiting enzyme that converts retinaldehyde to RA, was up-regulated in response to allergic stimulation in the airway epithelium, which indicates a possible site for RA production in the lung. ${ }^{60}$ Further, liposome-mediated delivery of RA 1 hour before immunization resulted in attenuated lung inflammation compared with control mice that received empty liposomes. Similarly, Citral, an inhibitor of RALDH-1, resulted in reduced synthesis of RA and fewer Tregs in the lung. Moreover, Calcitriol, an active form of vitamin $\mathrm{D}$, has been shown to reverse the defect in $\mathrm{IL}-10$ secretion by Tregs in glucocorticoid resistant patients. ${ }^{61}$

Several studies have demonstrated that glucocorticoids beneficially influence Tregs. For example, patients receiving glucocorticoids had higher levels of CD4+CD25+ Tregs and Foxp3 mRNA in peripheral blood cells compared with untreated asthmatics. ${ }^{62}$ The combination of glucocorticoids and 1,25-dihydroxyvitamin D3 or Calcitriol has been shown to induce IL-10-producing Tregs. Taking these findings into account along with recent advances in understanding Tregs and peripheral tolerance mechanisms, safer 
and long-lasting therapies for allergic asthma may arrive in the near future.

\section{Conclusion}

Foxp3+ Tregs play a critical role in maintaining tolerance to allergens and inhibit allergy and asthma. Changes in the balance between allergen-specific Tregs and effector Th2 and Th17 cells are crucial in the development of effective therapies to allergic diseases. In addition to therapeutic strategies for established allergy, it is essential to consider prophylactic approaches to prevent allergy before the initial sensitization occurs. Developing vaccines that induce allergen-specific Tregs to dampen allergic inflammation, thus ensuring a well balanced immune response, represents a promising avenue.

\section{Acknowledgment}

We thank Dr. Wei-Zen Wei for support and critical reading of the manuscript.

\section{References}

1. Herrick CA, Bottomly $\mathrm{K}$ : To respond or not to respond: $t$ cells in allergic asthma. Nat Rev Immunol 2003, 3:405-412

2. Shirakawa T, Enomoto T, Shimazu S, Hopkin JM: The inverse association between tuberculin responses and atopic disorder. Science 1997, 275:77-79

3. Hansen G, Berry G, DeKruyff RH, Umetsu DT: Allergen-specific Th1 cells fail to counterbalance Th2 cell-induced airway hyperreactivity but cause severe airway inflammation. J Clin Invest 1999, 103:175-183

4. Dahl ME, Dabbagh K, Liggitt D, Kim S, Lewis DB: Viral-induced T helper type 1 responses enhance allergic disease by effects on lung dendritic cells. Nat Immunol 2004, 5:337-343

5. Randolph DA, Stephens R, Carruthers CJ, Chaplin DD: Cooperation between Th1 and Th2 cells in a murine model of eosinophilic airway inflammation. J Clin Invest 1999, 104:1021-1029

6. Martin RJ, Boguniewicz M, Henson JE, Celniker AC, Williams M, Giorno RC, Leung DY: The effects of inhaled interferon gamma in normal human airways. Am Rev Respir Dis 1993, 148:1677-1682

7. Sheikh A, Smeeth L, Hubbard R: There is no evidence of an inverse relationship between $\mathrm{TH} 2$-mediated atopy and TH1-mediated autoimmune disorders: lack of support for the hygiene hypothesis. J Allergy Clin Immunol 2003, 111:131-135

8. Umetsu DT, DeKruyff $\mathrm{RH}$ : The regulation of allergy and asthma. Immunol Rev 2006, 212:238-255

9. Venuprasad K, Elly C, Gao M, Salek-Ardakani S, Harada Y, Luo JL, Yang C, Croft M, Inoue K, Karin M, Liu YC: Convergence of Itchinduced ubiquitination with MEKK1-JNK signaling in Th2 tolerance and airway inflammation. J Clin Invest 2006, 116:1117-1126

10. Kong Y, Morris GP, Brown NK, Yan Y, Flynn JC, David CS: Autoimmune thyroiditis: a model uniquely suited to probe regulatory $T$ cell function. J Autoimmun 2009, 33:239-246

11. Sakaguchi S, Yamaguchi T, Nomura T, Ono M: Regulatory T cells and immune tolerance. Cell 2008, 133:775-787

12. Kong YM, Giraldo AA, Waldmann H, Cobbold SP, Fuller BE: Resistance to experimental autoimmune thyroiditis: I3T4+ cells as mediators of both thyroglobulin-activated and TSH-induced suppression. Clin Immunol Immunopathol 1989, 51:38-54

13. Sakaguchi S, Sakaguchi N, Asano M, Itoh M, Toda M: Immunologic self-tolerance maintained by activated T cells expressing IL-2 receptor alpha-chains (CD25). Breakdown of a single mechanism of selftolerance causes various autoimmune diseases. J Immunol 1995, 155:1151-1164

14. Burchill MA, Yang J, Vang KB, Farrar MA: Interleukin-2 receptor signaling in regulatory $T$ cell development and homeostasis. Immunol Lett 2007, 114:1-8

15. Burchill MA, Yang J, Vang KB, Moon JJ, Chu HH, Lio CW, Vegoe AL, Hsieh CS, Jenkins MK, Farrar MA: Linked T cell receptor and cytokine signaling govern the development of the regulatory $T$ cell repertoire. Immunity 2008, 28:112-121

16. Lio CW, Hsieh CS: A two-step process for thymic regulatory $\mathrm{T}$ cell development. Immunity 2008, 28:100-111

17. Vang KB, Yang J, Pagan AJ, Li LX, Wang J, Green JM, Beg AA, Farrar MA: CD28 and C-Rel-dependent pathways initiate regulatory $T$ cell development. J Immunol 2010, in press

18. Molinero LL, Yang J, Gajewski T, Abraham C, Farrar MA, Alegre ML: CARMA1 controls an early checkpoint in the thymic development of FoxP3+ regulatory T cells. J Immunol 2009, 182:6736-6743

19. Long M, Park SG, Strickland I, Hayden MS, Ghosh S: Nuclear factorkappaB modulates regulatory $T$ cell development by directly regulating expression of Foxp3 transcription factor. Immunity 2009, 31:921-931

20. Ruan Q, Kameswaran V, Tone Y, Li L, Liou HC, Greene MI, Tone M, Chen $\mathrm{YH}$ : Development of Foxp3 $(+)$ regulatory t cells is driven by the c-Rel enhanceosome. Immunity 2009, 31:932-940

21. Vang KB, Yang J, Mahmud SA, Burchill MA, Vegoe AL, Farrar MA: IL-2, -7 , and -15 , but not thymic stromal lymphopoeitin, redundantly govern CD4+Foxp3+ regulatory $\mathrm{T}$ cell development. J Immunol 2008, 181:3285-3290

22. Fontenot JD, Rasmussen JP, Gavin MA, Rudensky AY: A function for interleukin 2 in Foxp3-expressing regulatory T cells. Nat Immunol 2005, 6:1142-1151

23. Burchill MA, Yang J, Vogtenhuber C, Blazar BR, Farrar MA: IL-2 receptor beta-dependent STAT5 activation is required for the development of Foxp3+ regulatory T cells. J Immunol 2007, 178:280-290

24. Li MO, Wan YY, Sanjabi S, Robertson AK, Flavell RA: Transforming growth factor-beta regulation of immune responses. Annu Rev Immunol 2006, 24:99-146

25. Liu Y, Zhang P, Li J, Kulkarni AB, Perruche S, Chen W: A critical function for TGF-beta signaling in the development of natural CD4+CD25+Foxp3+ regulatory $T$ cells. Nat Immunol 2008, 9:632-640

26. Bautista JL, Lio CW, Lathrop SK, Forbush K, Liang Y, Luo J, Rudensky AY, Hsieh CS: Intraclonal competition limits the fate determination of regulatory $T$ cells in the thymus. Nat Immunol 2009, 10:610-617

27. Chen W, Jin W, Hardegen N, Lei KJ, Li L, Marinos N, McGrady G, Wahl SM: Conversion of peripheral CD4+CD25- naive $T$ cells to CD4+CD25+ regulatory $T$ cells by TGF-beta induction of transcription factor Foxp3. J Exp Med 2003, 198:1875-1886

28. Apostolou I, von Boehmer $\mathrm{H}$ : In vivo instruction of suppressor commitment in naive T cells. J Exp Med 2004, 199:1401-1408

29. Mucida D, Kutchukhidze N, Erazo A, Russo M, Lafaille JJ, Curotto de Lafaille MA: Oral tolerance in the absence of naturally occurring Tregs. J Clin Invest 2005, 115:1923-1933

30. Zhou G, Levitsky HI: Natural regulatory T cells and de novo-induced regulatory $\mathrm{T}$ cells contribute independently to tumor-specific tolerance. J Immunol 2007, 178:2155-2162

31. Horwitz DA, Zheng SG, Gray JD: Natural and TGF-beta-induced Foxp3(+)CD4(+) CD25(+) regulatory T cells are not mirror images of each other. Trends Immunol 2008, 29:429-435

32. Zheng SG, Wang JH, Stohl W, Kim KS, Gray JD, Horwitz DA: TGFbeta requires CTLA-4 early after T cell activation to induce FoxP3 and generate adaptive CD4+CD25+ regulatory cells. J Immunol 2006, 176:3321-3329

33. Floess S, Freyer J, Siewert C, Baron U, Olek S, Polansky J, Schlawe K, Chang HD, Bopp T, Schmitt E, Klein-Hessling S, Serfling E, Hamann A, Huehn J: Epigenetic control of the foxp3 locus in regulatory T cells. PLoS Biol 2007, 5:e38

34. Dong C: TH17 cells in development: an updated view of their molecular identity and genetic programming. Nat Rev Immunol 2008, 8:337-348

35. Doganci A, Eigenbrod T, Krug N, De Sanctis GT, Hausding M, Erpenbeck VJ, Haddad el B, Lehr HA, Schmitt E, Bopp T, Kallen KJ, Herz U, Schmitt S, Luft C, Hecht O, Hohlfeld JM, Ito H, Nishimoto N, Yoshizaki K, Kishimoto T, Rose-John S, Renz H, Neurath MF, Galle PR, Finotto S: The IL-6R alpha chain controls lung CD4+CD25+ Treg development and function during allergic airway inflammation in vivo. J Clin Invest 2005, 115:313-325 
36. Zhou L, Chong MM, Littman DR: Plasticity of CD4+ T cell lineage differentiation. Immunity 2009, 30:646-655

37. Mucida D, Park Y, Kim G, Turovskaya O, Scott I, Kronenberg M, Cheroutre H: Reciprocal TH17 and regulatory T cell differentiation mediated by retinoic acid. Science 2007, 317:256-260

38. Coombes JL, Siddiqui KR, Arancibia-Carcamo CV, Hall J, Sun CM, Belkaid Y, Powrie F: A functionally specialized population of mucosal CD103+ DCs induces Foxp3+ regulatory T cells via a TGF-beta and retinoic acid-dependent mechanism. J Exp Med 2007, 204:1757-1764

39. Sun CM, Hall JA, Blank RB, Bouladoux N, Oukka M, Mora JR, Belkaid Y: Small intestine lamina propria dendritic cells promote de novo generation of Foxp3 T reg cells via retinoic acid. J Exp Med 2007, 204:1775-1785

40. Xiao S, Jin H, Korn T, Liu SM, Oukka M, Lim B, Kuchroo VK: Retinoic acid increases Foxp3+ regulatory $T$ cells and inhibits development of Th17 cells by enhancing TGF-beta-driven Smad3 signaling and inhibiting IL-6 and IL-23 receptor expression. J Immunol 2008, 181:2277-2284

41. Hill JA, Hall JA, Sun CM, Cai Q, Ghyselinck N, Chambon P, Belkaid Y, Mathis D, Benoist C: Retinoic acid enhances Foxp3 induction indirectly by relieving inhibition from CD4+CD44hi Cells. Immunity 2008, 29:758-770

42. Mucida D, Pino-Lagos K, Kim G, Nowak E, Benson MJ, Kronenberg M, Noelle RJ, Cheroutre H: Retinoic acid can directly promote TGFbeta-mediated Foxp3(+) Treg cell conversion of naive T cells. Immunity 2009, 30:471-472; author reply 472-473

43. Mantel PY, Ouaked N, Ruckert B, Karagiannidis C, Welz R, Blaser K, Schmidt-Weber CB: Molecular mechanisms underlying FOXP3 induction in human T cells. J Immunol 2006, 176:3593-3602

44. Kim HP, Leonard WJ: CREB/ATF-dependent T cell receptor-induced FoxP3 gene expression: a role for DNA methylation. J Exp Med 2007, 204:1543-1551

45. Tone Y, Furuuchi K, Kojima Y, Tykocinski ML, Greene MI, Tone M: Smad3 and NFAT cooperate to induce Foxp3 expression through its enhancer. Nat Immunol 2008, 9:194-202

46. Yao Z, Kanno Y, Kerenyi M, Stephens G, Durant L, Watford WT, Laurence A, Robinson GW, Shevach EM, Moriggl R, Hennighausen L, Wu C, O'Shea JJ: Nonredundant roles for Stat5a/b in directly regulating Foxp3. Blood 2007, 109:4368-4375

47. Venuprasad K, Huang H, Harada Y, Elly C, Subramaniam M, Spelsberg T, Su J, Liu YC: The E3 ubiquitin ligase Itch regulates expression of transcription factor Foxp3 and airway inflammation by enhancing the function of transcription factor TIEG1. Nat Immunol 2008, 9:245-253

48. Lal G, Zhang N, van der Touw W, Ding Y, Ju W, Bottinger EP, Reid SP, Levy DE, Bromberg JS: Epigenetic regulation of Foxp3 expression in regulatory T cells by DNA methylation. J Immunol 2009, 182:259-273

49. Kearley J, Barker JE, Robinson DS, Lloyd CM: Resolution of airway inflammation and hyperreactivity after in vivo transfer of CD4+CD25+ regulatory T cells is interleukin 10 dependent. J Exp Med 2005, 202:1539-1547

50. Lewkowich IP, Herman NS, Schleifer KW, Dance MP, Chen BL,
Dienger KM, Sproles AA, Shah JS, Kohl J, Belkaid Y, Wills-Karp M: $\mathrm{CD} 4+\mathrm{CD} 25+\mathrm{T}$ cells protect against experimentally induced asthma and alter pulmonary dendritic cell phenotype and function. J Exp Med 2005, 202:1549-1561

51. Lee JH, Yu HH, Wang LC, Yang YH, Lin YT, Chiang BL: The levels of $\mathrm{CD} 4+\mathrm{CD} 25+$ regulatory $T$ cells in paediatric patients with allergic rhinitis and bronchial asthma. Clin Exp Immunol 2007, 148:53-63

52. Wan YY, Flavell RA: Regulatory T-cell functions are subverted and converted owing to attenuated Foxp3 expression. Nature 2007 $445: 766-770$

53. Zhou X, Bailey-Bucktrout SL, Jeker LT, Penaranda C, MartinezLlordella M, Ashby M, Nakayama M, Rosenthal W, Bluestone JA: Instability of the transcription factor Foxp3 leads to the generation of pathogenic memory T cells in vivo. Nat Immunol 2009, 10:1000-1007

54. Nembrini C, Marsland BJ, Kopf M: IL-17-producing T cells in lung immunity and inflammation. J Allergy Clin Immunol 2009, 123:986994; quiz 995-986

55. Schnyder-Candrian S, Togbe D, Couillin I, Mercier I, Brombacher F Quesniaux V, Fossiez F, Ryffel B, Schnyder B: Interleukin-17 is a negative regulator of established allergic asthma. J Exp Med 2006, 203:2715-2725

56. Cheung PF, Wong CK, Lam CW: Molecular mechanisms of cytokine and chemokine release from eosinophils activated by IL-17A. IL-17F, and IL-23: implication for Th17 lymphocytes-mediated allergic inflammation. J Immunol 2008, 180:5625-5635

57. Rahman MS, Yamasaki A, Yang J, Shan L, Halayko AJ, Gounni AS: IL-17A induces eotaxin-1/CC chemokine ligand 11 expression in human airway smooth muscle cells: role of MAPK (Erk1/2. JNK, and p38) pathways. J Immunol 2006, 177:4064-4071

58. Ostroukhova M, Seguin-Devaux C, Oriss TB, Dixon-McCarthy B, Yang L, Ameredes BT, Corcoran TE, Ray A: Tolerance induced by inhaled antigen involves CD4(+) T cells expressing membranebound TGF-beta and FOXP3. J Clin Invest 2004, 114:28-38

59. Akbari O, DeKruyff RH, Umetsu DT: Pulmonary dendritic cells producing IL-10 mediate tolerance induced by respiratory exposure to antigen. Nat Immunol 2001, 2:725-731

60. Goswami S, Angkasekwinai P, Shan M, Greenlee KJ, Barranco WT Polikepahad S, Seryshev A, Song LZ, Redding D, Singh B, Sur S, Woodruff P, Dong C, Corry DB, Kheradmand F: Divergent functions for airway epithelial matrix metalloproteinase 7 and retinoic acid in experimental asthma. Nat Immunol 2009, 10:496-503

61. Xystrakis E, Kusumakar S, Boswell S, Peek E, Urry Z, Richards DF, Adikibi T, Pridgeon C, Dallman M, Loke TK, Robinson DS, Barrat FJ, O'Garra A, Lavender P, Lee TH, Corrigan C, Hawrylowicz CM: Reversing the defective induction of IL-10-secreting regulatory $\mathrm{T}$ cells in glucocorticoid-resistant asthma patients. J Clin Invest 2006, 116: $146-155$

62. Karagiannidis C, Akdis M, Holopainen P, Woolley NJ, Hense G Ruckert B, Mantel PY, Menz G, Akdis CA, Blaser K, Schmidt-Weber CB: Glucocorticoids upregulate FOXP3 expression and regulatory T cells in asthma. J Allergy Clin Immunol 2004, 114:1425-1433 